Anales de Geografía de la Universidad Complutense ISSN: 0211-9803

http://dx.doi.org/10.5209/AGUC.60467

\title{
Turberas y deforestación: la evolución del paisaje a través de las fuentes documentales (Bonales de Puebla de Don Rodrigo, Ciudad Real)
}

\author{
Concepción Fidalgo Hijano; Juan Antonio González Martín²; Rosario García Gimenez \\ Carlos Arteaga Cardineau ${ }^{4}$; María Luisa Colmenero ${ }^{5}$
}

Recibido: 6 de julio del 2016 / Enviado a evaluar: 26 de julio del 2016 / Aceptado: 14 de diciembre del 2017

Resumen. El entorno de Puebla de Don Rodrigo (Ciudad Real) constituye una de las zonas de mayor interés paisajístico del interior de la Península Ibérica debido, entre otras razones, a la presencia de un conjunto de turberas ácidas de reducida extensión, denominadas localmente "bonales". El presente trabajo se centra en el análisis de las singulares características del paisaje de este territorio, esencialmente desde el siglo XVI. El conocimiento de las condiciones imperantes en aquellos momentos, algunos de los cuales se corresponden con etapas álgidas de la denominada Pequeña Edad del Hielo, permitirá iluminar la evolución experimentada por estos humedales hasta el momento actual, infiriendo que una intensa y secular deforestación es responsable de la génesis de las transformaciones del medio, y en concreto del desarrollo de los encharcamientos que ha permitido la aparición de estos humedales higroturbosos de enorme valor natural.

Palabras clave: Bonales; turberas; fuentes documentales; deforestación.

[en] Bogs and deforestation: the evolution of landscape through the documentary sources (Bonales of Puebla de Don Rodrigo, Ciudad Real)

\begin{abstract}
The surroundings of Puebla de Don Rodrigo (Ciudad Real) constitute one of the areas of greatest natural interest inside the Iberian Peninsula among other reasons, due to the presence of a set of acidic peat bogs of reduced extension known locally as "bonales". This paper focuses on the analysis of the singular features in the landscape of this territory, especially from the sixteenth century.
\end{abstract}

1 Departamento de Geografía. Universidad Autónoma de Madrid.

E-mail: concepcion.fidalgo@uam.es

2 Departamento de Geografía. Universidad Autónoma de Madrid.

E-mail: juanantonio.gonzalez@uam.es

3 Departamento de Geología y Geoquímica. Universidad Autónoma de Madrid.

E-mail: rosario.garcia@uam.es

4 Departamento de Geografía. Universidad Autónoma de Madrid.

E-mail: carlos.arteaga@uam.es

5 Servicio Medio Ambiente, Ciudad Real. Juanta de Comunidades de Castilla-La Mancha

E-mail: mcolmenero@jccm.es 
Knowing the conditions at the time, some of which corresponded to cold events so-called Little Ice Age, will allow enlighten of the evolution experienced by these wetlands to date, inferring that a secular and intense deforestation is responsible of the genesis of the transformations of the environment. Also, and specifically, it is the cause of the development of waterlogging which has allowed the presence of these peaty wetlands of great natural value.

Key words: Peatlands; bogs; documentary sources; deforestation.

\section{[fr] Bogs et déforestation: l'evolution du paysage sur les sources documentaires (Bonales de Puebla de Don Rodrigo, Ciudad Real)}

Résumé. Les environs de Puebla de Don Rodrigo (Ciudad Real) constituent l'une des zones de plus grand intérêt naturel à l'intérieur de la Péninsule Ibérique à cause de la présence, entre autres raisons, d'un ensemble de tourbières acides d'extension réduite, connues localement comme "bonales". Ce document met l'accent sur la reconstruction des caractéristiques principales dans le paysage de ce territoire, essentiellement depuis le XVIe siècle ; La connaissance des conditions à l'époque, dont certains correspondent à étapes algides de la soi-disant Petit Age Glaciaire, permettra éclairer l'évolution vécue par ces zones humides à ce jour, et inférer qu'une intense et séculaire déforestation est en la genèse des transformations de l'environnement, et plus particulièrement dans le développement de l'engorgement qui a permis l'émergence de ces zones humides tourbeuses de grande valeur naturelle.

Mots clés: Bonales; tourbières; sources documentaires; déboisement.

Cómo citar. Fidalgo Hijano, C., González Martín, J.A., García Jiménez, R., Ateaga Cardineau, C. y Colmenero, M.L. (2018): Turberas y deforestación: la evolución del paisaje a través de las fuentes documentales (Bonales de Puebla de Don Rodrigo, Ciudad Real). Anales de Geografía de la Universidad Complutense, 38(1), 11-34.

Sumario. 1. Introducción. 2. Localización y caracterización de la zona de estudio. 3. Fuentes documentales para el estudio de la evolución del paisaje. 3.1. Noticias anteriores al siglo XVI. 3.2. Información sobre el medio natural y la deforestación en el siglo XVI. 3.3. El avance de la deforestación: la situación en el siglo XVIII. 3.4. Los siglos XIX y XX, la primera mención a la existencia de prados naturales. 4. Conclusiones. 5. Bibliografía.

\section{Introducción}

El objeto de esta investigación es un conjunto de turberas ácidas de extensión reducida, localizadas en el interior de la Península Ibérica (localidad de Puebla de Don Rodrigo, Ciudad Real, Spain) (Figura 1), cuya singularidad ha merecido el reconocimiento de distintas figuras de protección:

- LIC Bonales de la comarca de Los Montes del Guadiana ES4220019. Los términos municipales que abarca el LIC son: Arroba de los Montes, Fontanarejo, Piedrabuena, Puebla de Don Rodrigo (Ciudad Real).

- Hábitat del Anexo I de la Directiva 92/43/CEE y Microrreserva, En el caso de la localidad de Puebla de Don Rodrigo se han definido como Microrreservas los siguientes bonales: Microrreserva Bonales de Puebla de Don Rodrigo Decreto 42/2002, de 2 de abril con una extensión de 64,00 ha.; Microrreserva Bonal del Barranco del Chorro - Decreto 118/2002, de 3 de septiembre, 17,63 
ha; Microrreserva Bonal del Barranco del Remilladero - Decreto 14/2003, de 4 de febrero, 31,58 ha; Microrreserva Bonal del Barranco de los Membrillos Decreto 16/2003, de 4 de febrero, 6,85 ha.

- Habitats de protección especial definidos en la Ley 9/1999 de Conservación de la Naturaleza.

- Al mismo tiempo, muchas de las especies que se encuentran en estos bonales están incluidas en el Catálogo Regional de Especies Amenazadas de CastillaLa Mancha.

Figura 1. Ubicación del Pueblo de Don Rodrigo, Ciudad Real y localización de algunos topónimos ${ }^{6}$.

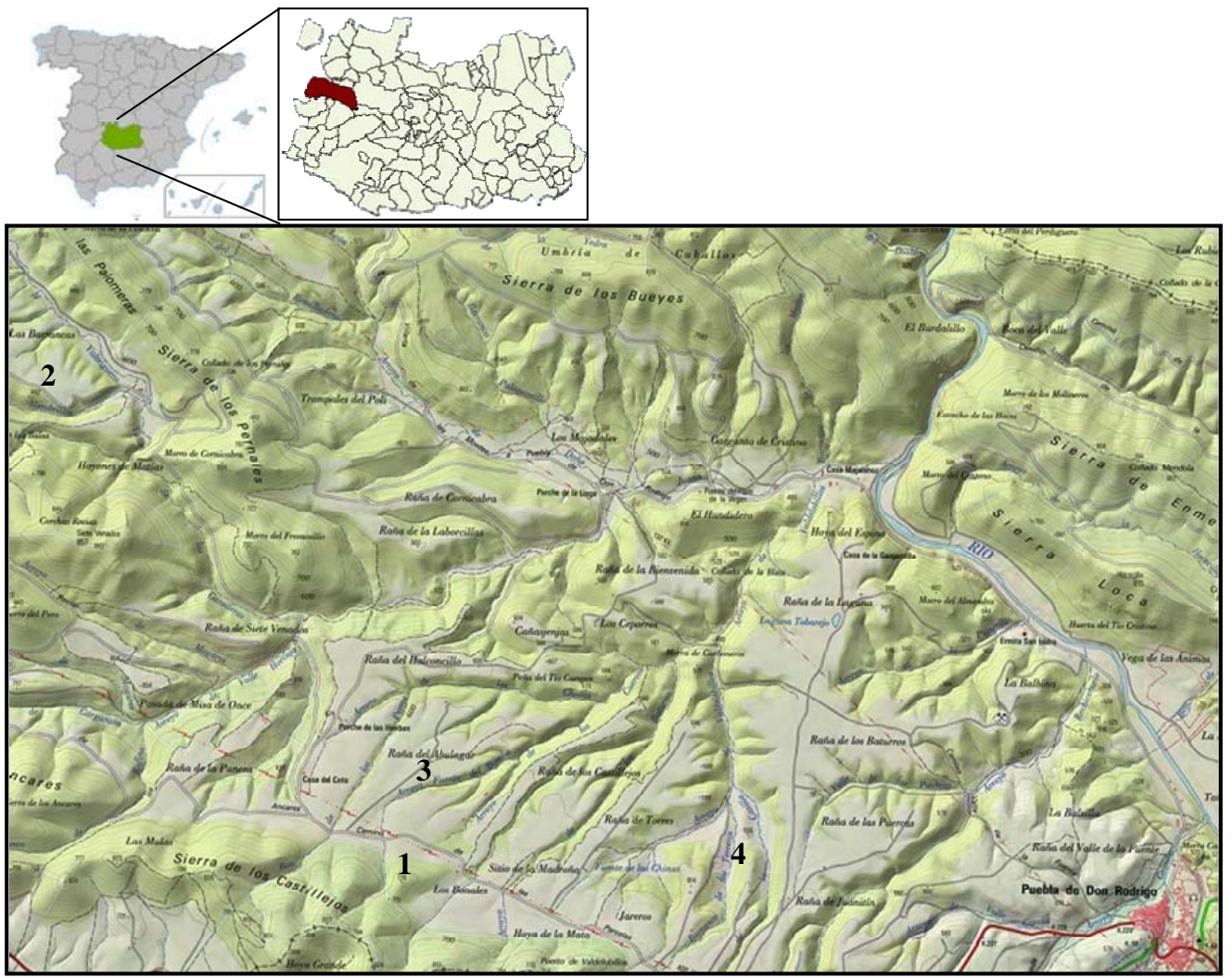

Fuente: Detalle del mapa Topográfico Nacional 1/50000, hoja 0757, 2007, Puebla de Don Rodrigo. I.G.N.

\footnotetext{
${ }^{6}$ Localización de algunos topónimos: 1. Los Bonales. 2. Bonal de los Membrillos. 3. Raña del Abulagar. 4. Barranco de los Terreros.
} 
Se trata de humedales higroturbosos denominados localmente "bonales o trampales". Ambos términos tienen un significado preciso para los habitantes de la región $\mathrm{y}$, de hecho, forman parte de la toponimia menor (Arroyo de los Bonales, Sierra de los Bonales, Trampal del Perro, etc.) (García Río, 2001). Aluden a humedales cuya característica específica es no ofrecer una lámina de agua libre, sino un encharcamiento que empapa el suelo (Molina Martín, 2009). Presentan una elevada dispersión territorial, reducido tamaño y un emplazamiento en depresiones fluviales alimentadas por flujos de aguas superficiales y subsuperficiales. Su originalidad radica en la localización, un ámbito climático mediterráneo y una posición latitudinal y altitudinal peculiar. En la Península Ibérica, la mayor parte de las turberas se ubica en zonas más lluviosas (Portugal o Galicia) o en montañas más altas y frías (Pirineos, Cordillera Cantábrica, Sistema Central o Sistema Ibérico). Por ello es especialmente relevante el desarrollo de estos humedales en un dominio interior (García Río, 2000, 2001, 2002 y 2007; Florín Beltrán, 2012). No obstante, la humedad permanente los convierte en elementos paisajísticos destacados con abundante agua, suelo turboso y vegetación específica - refugio de especies atlánticas, de óptimo centroeuropeo y boreales- en medio de un terreno influido por el clima mediterráneo.

Recientes investigaciones han abordado el análisis de la ecología y grado de conservación de estas turberas (López Sáez et al., 2014/2015, García Rio, 2001 y 2002) y en ellas se ha puesto de manifiesto su enorme riqueza florística y la presencia de especies vegetales amenazadas y singulares.

El objetivo de la presente investigación es precisar su génesis, considerando que sólo el conocimiento de los procesos que han originado la aparición de estos hábitats permitirá explicar su evolución. Se aborda un estudio que, a través de la información de las fuentes documentales, permite reconocer el papel que el hombre ha desempeñado a lo largo de la historia en estos ecosistemas.

La influencia de la acción humana en la creación de hábitats singulares es una cuestión a debate en el momento actual. Son numerosas las aproximaciones que han suscitado una reflexión sobre el origen y la evolución de espacios de enorme interés, y donde cabe preguntarse si su génesis es natural o antrópica. Este puede ser el caso de algunas turberas entre las cuales se encuentran las de la zona de estudio, originadas de manera indirecta por la acción del hombre sobre el entorno $\mathrm{y}$, en particular, sobre los flujos de agua (Bragg et al. 2001; De Miguel, 2006; Vautier et al. 2010).

Este trabajo tiene por objeto avanzar en el conocimiento de las condiciones ambientales que convergieron en el paisaje de este territorio y donde la intervención del hombre ha sido intensa a lo largo de los siglos, sobre todo a partir de la centuria del XVI. Se apoya en la consulta de diferentes fuentes documentales, con distinta cronología y naturaleza (textuales y cartográficas), conservadas en distintos archivos de rango nacional (Archivo Histórico Nacional), provincial (Archivo Histórico Provincial de Ciudad Real) y municipal (Archivo Municipal de Puebla de Don Rodrigo). Estas fuentes proporcionan información acerca de estos originales parajes, la valoración que ofrecían a la población, el uso de los mismos, etc. A partir 
de su análisis es posible por un lado, efectuar una aproximación a los elementos y dinámicas reinantes en el territorio, precisamente en etapas de gran interés climático al coincidir con las rigurosas fases de la Pequeña Edad del Hielo; por otro, permite seguir algunos jalones de la evolución registrada en estos reducidos humedales hasta el momento actual. En ella sobresale una intensa deforestación, como principal responsable de las modificaciones experimentadas por el medio y, de modo especial, en el desarrollo de unos encharcamientos que favorecieron el emplazamiento de unos conjuntos higroturbosos de enorme valor natural.

\section{Localización y caracterización de la zona de estudio}

El municipio de Puebla de Don Rodrigo se integra en la Comarca de Montes, provincia de Ciudad Real (Castilla-La Mancha) y en la Mancomunidad de Cabañeros.

Geológicamente se inserta en el Macizo Hespérico meridional (García Rayego, 1997a), zócalo constituido por roquedos intensamente plegados y fracturados en varias épocas de la orogenia varisca. Los más antiguos son de edad precámbrica y se asocian a un conjunto de discontinuos afloramientos de pizarras y grauvacas sobre los que yace, en discordancia, una potente serie de materiales ordovícicos (I.T.G.E, 1989); sobre todo cuarcitas, cuya resistencia a la erosión motiva que las cimas de las numerosas sierras que estructuran el relieve de esta zona coincidan, casi siempre, con esta litología. El territorio está conformado por una montaña media de fragosa morfología apalachense, cuyas cumbres se alzan entre 800 y 900 $\mathrm{m}$ de altitud mientras que las depresiones rondan los 450-500 m (Hernández Pacheco y Cabañas Ruesgas, 1952; Mingarro Martín, 1959); situándose la localidad de Puebla de Don Rodrigo a unos $490 \mathrm{~m}$ y asomada al cauce del río Guadiana que fluye por su entorno con un trazado general de SE-NW interrumpido en ocasiones por ciertos meandros. Entre cumbres y talwegs se desarrollan unas vertientes, a veces con morfología de prolongada concavidad, y coronadas por fanglomerados asociados a las rañas pliocenas (I.T.G.E., 1989).

Las peculiaridades climáticas genéricas de la zona ofrecen unos registros térmicos anuales que, para el área de Puebla de Don Rodrigo, oscilarían entre $15^{\circ} \mathrm{y}$ $15,5^{\circ} \mathrm{C}$, con valores medios invernales entre $6^{\circ}$ y $7^{\circ} \mathrm{C}$ mientras que los estivales ascenderían hasta $\operatorname{los} 25^{\circ} \mathrm{C}$. Las precipitaciones anuales no son muy elevadas y fluctúan alrededor de los 600 mm en esta localidad (García Rayego, 1995 y 1997b).

Desde el punto de vista biogeográfico, el predominio lo ejerce la vegetación esclerófila mediterránea (serie luso-extremadurense mesomediterránea), protagonizada por dos especies: encina (Quercus ilex sp. ballota) y alcornoque (Quercus suber). El encinar está acompañado por una rosácea que constituye un elemento diferencial de esta comunidad, el piruétano o peral silvestre (Pyrus bourgaeana) y, en las áreas más húmedas o umbrías, por el quejigo (Quercus faginea). Estos encinares han sido sustituidos en extensas superficies por plantaciones de pino rodeno o resinero (Pinus pinaster). Una mayor humedad 
posibilita la presencia de alcornoque asentado principalmente en fondos de valle y umbrías.

Los bonales, a pesar de tratarse por lo general de enclaves aislados y de pequeñas dimensiones, constituyen hábitats exclusivos, en los que se desarrolla un micromosaico de comunidades vegetales, diferenciadas en función de diversos factores ecológicos entre los que se muestran, como determinantes, los correspondientes al régimen hídrico. Presentan una importante riqueza florística con especies singulares y endémicas que se desarrollan en hábitats muy restringidos y frágiles, como los brezales higrófilos de Erica tetralix y las comunidades de sphagnos. Además, algunos bonales contienen abombamientos turbosos o "vejigas" (como se les conoce en la zona) (Figura 2) que constituyen dispositivos de gran interés no sólo botánico sino también geomorfológico?

Figura 2. Abombamiento o vejiga de El Abulagar. Bonales de Puebla de Don Rodrigo.

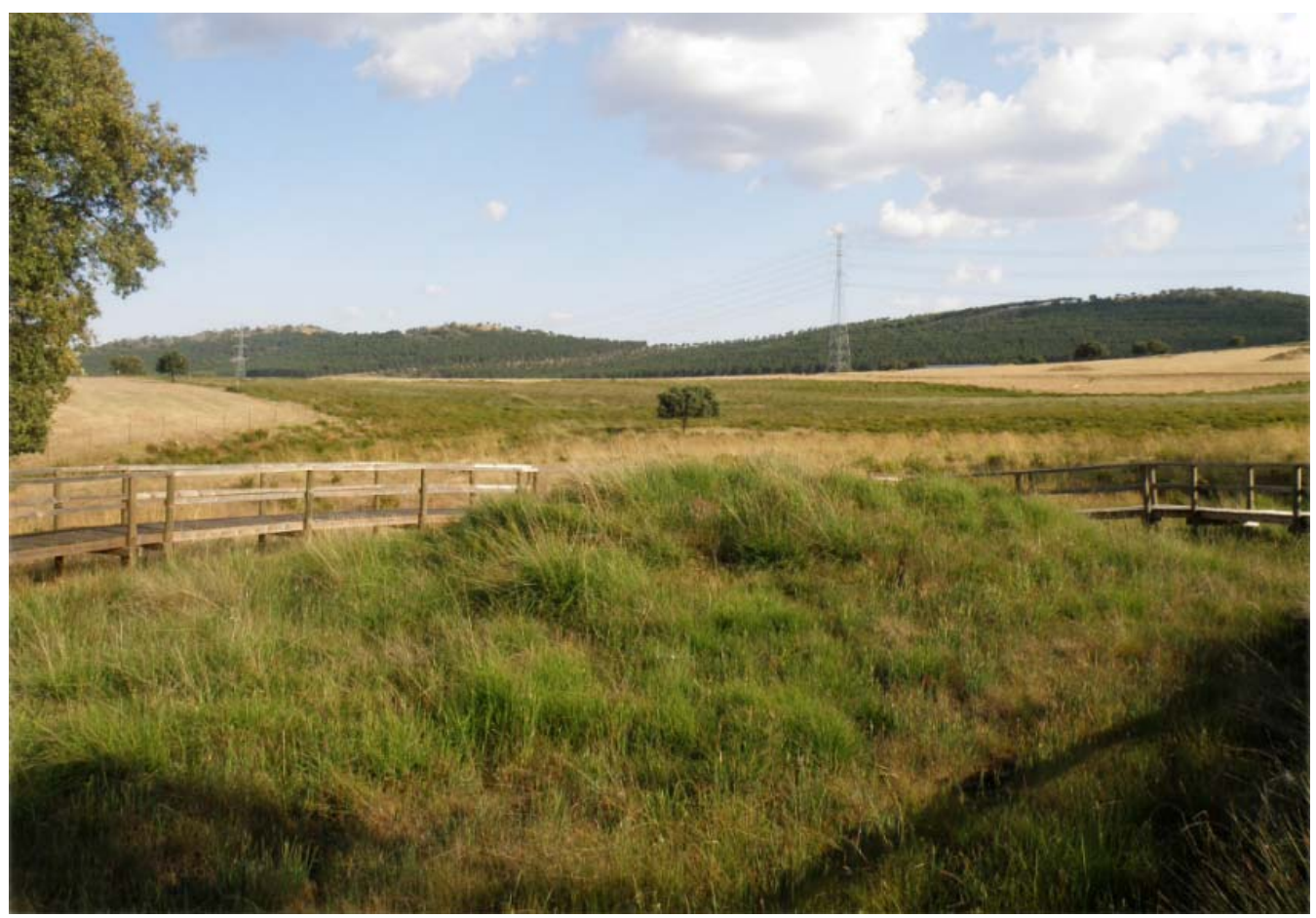

Fuente: Elaboración propia.

\footnotetext{
${ }^{7}$ La presencia actual y singularidad de estos humedales ha suscitado el interés por la realización de un trabajo de investigación, gestionado por la Junta de Comunidades de Castilla La Mancha, acerca de la evolución y génesis de estos parajes "Estudio Paleobotánico, Paleogeográfico dinámica y amenazas de la Microrreserva de los Bonales en el término municipal de Puebla de Don Rodrigo", 2013.
} 
La hipótesis de partida es que las vertientes de la zona debieron estar antaño cubiertas por masas de vegetación esclerófila que, en la actualidad, se reducen a formaciones arbóreas residuales, o incluso a ejemplares aislados, siendo de crucial interés concretar el momento en el que se inició el proceso deforestador. De igual modo es necesario conocer los cambios producidos en los usos del suelo, con un notable incremento de los cultivos a costa de las roturaciones del bosque que llegan a los límites de las zonas ocupadas por las formaciones higroturbosas, además del desarrollo en la ganadería o una importante actividad cinegética. A su indudable valor botánico, hay que añadir el hecho de que los bonales sirven de abrevadero para la fauna.

\section{Fuentes documentales para el estudio de la evolución del paisaje}

Las fuentes documentales en las que es factible recabar información sobre la evolución del medio natural son escasas, de muy diverso tipo y localizadas en fondos dispersos y con diferentes peculiaridades. Como es bien sabido, documentos esenciales en el conocimiento del paisaje durante los siglos XVI y XVIII, son las Relaciones Topográficas de Felipe II (1575) y las Respuestas Generales y Particulares del Catastro de Ensenada (1753), también han sido objeto de análisis el Libro de la Montería de Alfonso XI (siglo XIV), los diccionarios de Miñano (1828), Madoz (1846-1850) y Hervás (1914) o los expedientes de desamortización o legalización de propiedades (siglo XX).

\subsection{Noticias anteriores al siglo XVI}

Es difícil encontrar información sobre el medio físico en épocas anteriores al siglo XVI. En el Libro de la Monteria de Alfonso XI se reseñan varios montes de la zona limítrofe con los actuales términos de Piedrabuena, la Puebla y Saceruela, en los que aparecen nombrados el "Camino de la Barca", "La Celadilla", "El Val de Gavilanes" y "Castiel Negro", topónimos incluidos en la cartografía de los mapas publicados por el Instituto Geográfico Nacional. Según Hervás (1914), el 9 de febrero de 1217 el papa Honorio III emitió una Bula en Letrán concediendo a D. Rodrigo Jiménez de Rada, Arzobispo de Toledo las casas, viñas, molinos, hornos, sernas....de Zuferola con todos sus términos en Alarcos... hasta Avenoia y Cuevas del Guadiana. Así, en el siglo XIII, en la ubicación actual de la localidad, existía una precaria agrupación de viviendas que serviría de albergue a colmeneros y ganaderos con el nombre de Casas del Guadiana y era aldea de Piedrabuena. En mayo de 1472, el Maestre de Calatrava Don Rodrigo Téllez Girón la hizo villa y pasó a denominarse Puebla de Don Rodrigo Girón. Los términos de la villa no fueron bien establecidos por la Mesa Maestral en la carta o privilegio de villa y ello ocasionó numerosos pleitos con los pueblos vecinos y con el señor de Piedrabuena. 


\subsection{Información sobre el medio natural y la deforestación en el siglo XVI}

Para esta centuria se dispone de una valiosa y muy utilizada fuente documental que corresponde a las Relaciones Topográficas, cuyas respuestas, al interrogario, ordenado por Felipe II $^{8}$, permiten abordar la situación medioambiental de los territorios del centro peninsular durante ese periodo así como también una aproximación al conocimiento de su población, de los usos del suelo, etc.

Se comenzó afirmando que la villa se llamaba la Puebla de Don Rodrigo Girón y que pertenecía al partido de Almodóvar del Campo ${ }^{9}$, al reino de Toledo y a la Orden de Calatrava. Así en respuesta a la pregunta $7^{\mathrm{a}}$ de las Relaciones se afirma: este pueblo es de la Orden de Calatrava y es de su Majestad y lleva las rentas del don Diego Hernandez de Cordoba, comendador y Alonso de Mesa, señor de Piedrabuena. También en la pregunta $12^{\mathrm{a}}$ se ratifica su pertenencia a la Orden de Calatrava.

En relación con las características del entorno la zona fue calificada de tierra fría, aspera y muy cerca de montes y en sierra, aunque ella esta fundada en un llano, es muy enferma por razón de que los niños que se crian se hacen de grandes barrigas y mueren muchos de dolor de costado por ser muy frio de invierno y muy calido de verano. No hay ni una sola mención a problemas de tercianas por culpa de los encharcamientos. Por otra parte, la referencia a grandes barrigas (hinchazón abdominal) pudiera estar relacionada con algunas enfermedades vinculadas con contaminación por metales pesados, identificados durante la realización del proyecto mencionado (Fidalgo et al., 2013).

Respecto a las condiciones topográficas, la descripción que se hace del relieve menciona cómo la población está cercada por sierras a la parte de cierzo la Sierra de la Cigueruela y a la parte del mediodía la Sierra de Peñas Lisas...... desde las dos sierras corren las corrientes de una parte y de otra hacia el rio Guadiana que pasa entre ambas estas dos sierras. Respondieron que el río Guadiana no deja de correr siempre salvo en algún año muy seco, ni dejan los molinos de moler; igualmente, se citan dos arroyos por cuyos lechos siempre fluían las aguas: el arroyo de Valde las Cuebas y el del Mimbre. Existía pesca en el río Guadiana, pero

\footnotetext{
${ }^{8}$ Se ha utilizado la transcripción de los originales contenida en la Biblioteca Real de El Escorial presente en la obra de Campos y Fernández de Sevilla, 2009. Las personas que contestaron al interrogatorio, realizado el 7 de diciembre de 1575, fueron: Christobal Gonzales y Martin Fernandez (alcaldes) y junto a ellos se menciona a Pedro Sanchez Bonodal (regidor), Juan Lopez y Francisco Diez (jurados del ayuntamiento), Miguel Martin (procurador síndico del Concejo), Andres Gomez (alguacil mayor), Agustin Garcia (mayordomo del Concejo), Diego Garcia el viejo, Pablo Garcia, Pedro Lopez, y Juan Fernandez el mozo (vecinos de la villa). Una vez reunidos todos los anteriores nombraron a Diego Garcia del Spinar y a Pedro Hernandez Bodonal vecinos de esta villa para que respondieran a las preguntas (declarar los dichos capitulos). Llama la atención el apellido Bodonal o Bonodal que ostentan algunos de los que intervienen en las respuestas de las Relaciones Topográficas, tan similar a la denominación de bonales que reciben localmente los humedales.

${ }^{9}$ Suprimido éste a fines del siglo XVI pasó a formar parte del partido de Almagro. A comienzos del siglo XVII (1602) una vez restablecido el partido de Almodóvar del Campo quedó bajo la jurisdicción de su alcalde mayor
} 
no en los arroyos. Los flujos de éstos proveían de agua a la población y allí bebe la gente. En la respuesta $23^{\mathrm{a}}$ se describe que esta villa es abundosa de aguas.

En el río Guadiana se relata la existencia de tres molinos de muy poco valor por haber en ella mиy poco pan que moler. Respecto a las dehesas, poseía una dehesa boyal que era donde pasta el ganado de arada. Además de las dehesas de Vezallana, Dehesa Miño, el Arenal, Chueca, las Barcas y la dehesa de Cumajo, todas del señor de Piedrabuena. Respecto a la ganadería: algún ganado cabrio y en la respuesta a la pregunta $42^{\mathrm{a}}$ se dice que se crian algunos ganados cabrio y porcunos y no hay otras granjerías.

A la $45^{\text {a }}$ se contestó que la villa no tiene propio alguno ni puede vender sus términos por ser pasto común con Piedrabuena. En cuanto a los cultivos: se labra trigo, cebada y centeno y aunque se siembra se coge poco por los daños de los ganados monteses. Hay falta de vino y se provee de la Mancha. Todos los habitantes, en 1575, eran labradores y las casas eran de tapias y maderas todo lo cual se corta y se hace en el pueblo.

A partir de la información contenida en las respuestas a las Relaciones llama la atención la distribución de la tierra. Así puede establecerse un reparto de las tierras que, según Corchado Soriano (1982) sería 77\% para los montes comunes y el 21\% a las Dehesa de la Encomienda de Piedrabuena, quedando una superficie mínima (un $1 \%$ respectivamente) para la dehesa del Concejo y las tierras de particulares. La propiedad particular era muy escasa y se asentaba en los terrenos montuosos que roturaban mediante el procedimiento de hacer rozas. Esta práctica de rozar tierras montuosas para ponerlas en cultivo supone una nítida y eficaz práctica de deforestación. En las Relaciones se refiere que la tierra es muy fértil de leña y muy montuosa de xara y monte bravo, alcornoques, quejigos, robres, encinas, lantiscos, gaguanzo, madroño. Existían especies arbóreas típicas de la vegetación autóctona como encinas, alcornoques, quejigos o robles, pero junto a ellas se alude a especies arbustivas tales como el madroño, el lentisco (lantisco) o el jaguarzo (gaguanzo, Cistus sp.) siendo la primera especie mencionada la jara (xaras).

En cuanto a la fauna, se crian animales osos, lobos, xabalies, ciervos y ciervas, conexos y perdices y otros animales que se comen los panes y ganados que se crian. En clara referencia a la abundancia de animales salvajes.

En este momento histórico, la localidad tenía 80 vecinos, pero en 1652 descendieron a 30 (Hervás, 1914).

En 1619, en la Carta de confirmación y privilegios de villa, ratificados por los Reyes Católicos y Carlos V, y posteriormente firmados por Felipe II, se hace una clara alusión a los usos desarrollados en los montes. Se conceden privilegios para usar los montes para el cultivo y pacer ganadería de cabrío y porcino, así como utilizar las dehesas boyales conjuntamente con las propiedades del Señor de Piedrabuena. En esta centuria una de las medidas adoptadas por la Mesa Maestral, con el fin de aumentar la población, así como incrementar la producción agrícola y pecuaria, fue permitir la quema de monte para ganar tierras de cultivo (Rivero, 2003). Así pues, el proceso deforestador ya estaba plenamente en desarrollo en los siglos XVI y XVII. 


\subsection{El avance de la deforestación: la situación en el siglo XVIII}

En esta centuria se cuenta con otra fuente documental muy valiosa: el Catastro de Ensenada $^{10}$. Los datos que aporta son de gran utilidad para conocer éste y otros entornos pertenecientes a la Corona de Castilla, a mediados del siglo XVIII (Camarero, 2002), ya que permite comprender aspectos importantes de la evolución de sus paisajes y algunos de los factores que han intervenido en aquella ${ }^{11}$. No obstante, la información que proporciona relativa a los aspectos del medio físico es indirecta, aunque muy superior a lo que era norma en documentos de tipo fiscal como son los catastros. Es por ello que a partir de ella pueden obtenerse noticias de los aprovechamientos de los cursos fluviales y sus riberas o aspectos relativos al estado de las cubiertas vegetales.

Al inicio se afirma, siguiendo las mismas pautas que en el siglo XVI, que el nombre de la localidad era Puebla de Don Rodrigo, que pertenecía al territorio del Orden de Calatrava. Después establecen, en respuesta a la pregunta $3^{\text {a }}$, los límites municipales y acompañan la descripción con un mapa (Fig. 3) del término. En él, bellamente ilustrado, además del nombre de las poblaciones limítrofes se representa el río Guadiana y se intuye un arroyo (aroio) en las proximidades del núcleo de población. Llama la atención la presencia de una barca en el Guadiana.

La distribución de los tipos de tierra arroja valores de $71 \%$ para las Tierra del común de vecinos de Piedrabuena, $15 \%$ era considerada tierra inútil por naturaleza y el $13 \%$ pertenecía a las dehesas del Marqués de Montana (las tierras de cultivo, tanto de regadío como de secano, constituían una ínfima parte del total del término e, incluso, la dehesa boyal sólo representaba el 1\%) (Tabla 1). Esta distribución no es muy diferente a la plasmada para el siglo XVI en las Relaciones Topográficas de Felipe II: también más del 70\% (entonces llegaba al 77\%) de las tierras del término eran del común; la propiedad particular seguía siendo extremadamente reducida.

\footnotetext{
${ }^{10}$ Del Catastro de Ensenada Puebla de Don Rodrigo del Campo de Calatrava se han consultado: Memoriales, secular (memoriales común y posito (tierras baldias), Eclesiastico, Memoriales de los vecinos seglares, Autos generales, Antecedentes generales, Mapas, Extractos para mapas clase de tierra, Extractos. Libro de las casas avitables de eclesiásticos y bienes que posee el estado eclaesiático. Bienes de terratenientes eclesiásticos, Libro de lo Real.

${ }^{11}$ En este trabajo se ha utilizado esencialmente uno de los documentos contenido en el amplio corpus documental del Catastro de Ensenada: las Respuestas Generales, que recoge las contestaciones dadas por el concejo y peritos de todas y cada una de las 15.000 localidades de la Corona de Castilla. Proporcionan una foto fija de los municipios a mediados de aquella centuria. La fecha de realización del Catastro, en la localidad de Puebla de Don Rodrigo, fue el 10 de marzo de 1753 y las personas encargadas de responder al interrogario fueron los alcaldes ordinarios, Gregorio Santos y Diego González; Juan Vizente y Juan Barrio, regidores; Lorenzo Parla síndico Procurador; Fernando Cavallero escribano del Ayuntamiento; Domingo Pellejero el mayor, Gregorio Granizo, Juan Triguero, Diego Pajuela, Antonio Garzia y Pedro Granizo, vecinos de esta villa, y junto a ellos el Lizenziado Don Juan Basilio Quadrado cura theniente de la Parrochial de esta villa por impedimento del Lizenziado Don Luis Muñoz Zarate
} 
Figura 3. Mapa del término de Puebla de Don Rodrigo que acompaña a la pregunta $3^{\mathrm{a}}$ de las Respuestas Generales de dicha localidad.

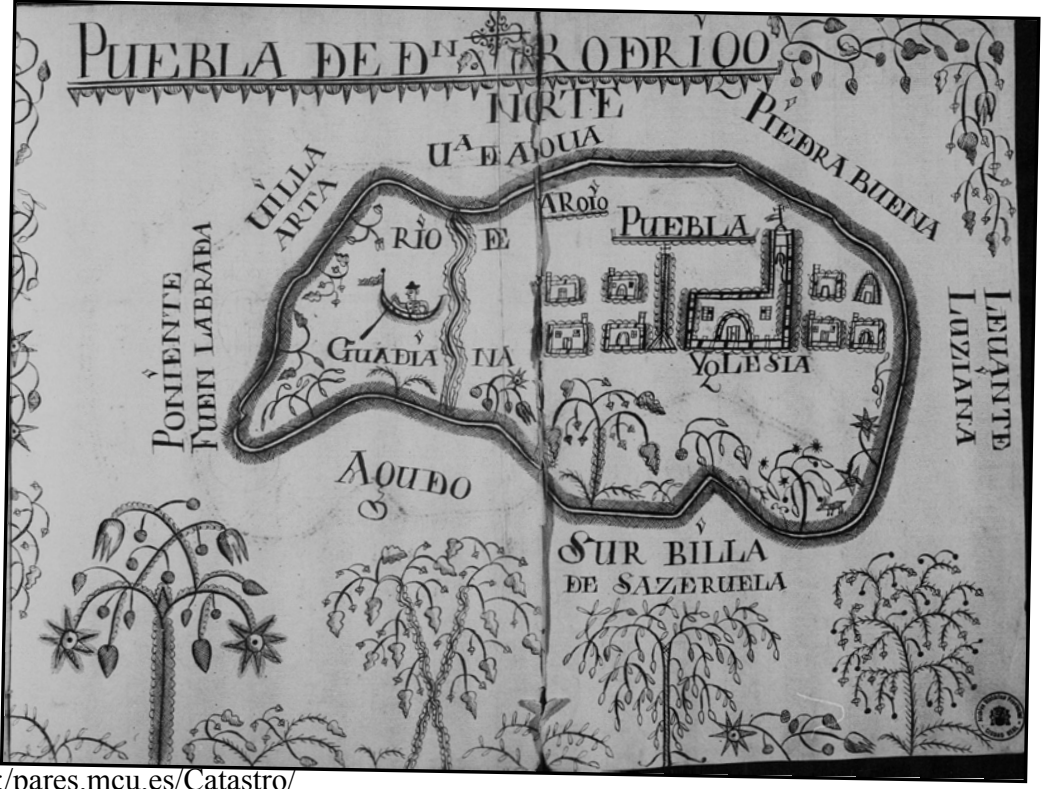

Fuente: http:/pares.mcu.es/Catastro/

El marqués de Montana, señor de la villa de Piedra Buena, tenía 7 dehesas en el término de Puebla: caveza de Asna, la de el nuño, el arenal, la Barca de retama, la de texa, la dehesa de Chueca y Cumajo que componen veinte mil y treinta...La mayor parte del término estaba ocupada por las tierras del común de vecinos con Piedrabuena, a ellas se refieren como tierras baldías: Las tierras valdias de el termino de estas villa que son comunes con la de Piedra Buena compondrán ciento treinta y ocho mil doszientas ochenta cuerdas según calculo que an echo de sus sitios, y de primera calidad seran las treinta fanegas de ellas, de la de segunda dos mil y quinientas, $y$ ziento $y$ treinta y zinco mil setezientas y zincuenta de la de terzera, que en estas abran una gran parte de tierra ynútil por ser el todo de ella montuosa; comprehenden muchas sierras y peñascales que sólo sirve para pastar ganado cabrio y bacuno en la que se mantiene el de el común en aquella parte que es de aprovechamiento (sic).

Fundamentalmente, las tierras del término eran de secano (a resaltar las dedicadas a trigo y cebada), se cultivaban dejando un año en descanso y se les denominaba "tierra de cercas"; las poseían los vecinos en la inmediación del pueblo; sólo una pequeña porción era de regadío por fuente y arroyo. Se sembraba incluso la "tierra montuosa" para trigo y cebada; para ello se procedía a rozar el monte de quince en quince años mediante "hojas de roza" en determinados lugares. Dentro de la categoría de tierra baldía incluían la montuosa poblada de monte bajo (con jaras, chaparros, enebros y otros matorrales) -la definían como "monte cerrado"- y las sierras y pedregales donde se pastaba. 
Tabla 1. Tipos de tierras en el término de Puebla de Don Rodrigo, según el Catastro de la Ensenada.

\begin{tabular}{|c|c|c|}
\hline TIPOS DE TIERRA & SUPERFICIE (cuerdas) & DISTRIBUCIÓN PORCENTUAL (\%) \\
\hline TIERRAS DE REGADIO POR FUENTE & 19,8 & 0 \\
\hline TIERRAS DE SEMBRADURA Y SECANO & 543,9 & 0 \\
\hline TIERRA PROPIA PARA ROZAS & 438 & 0 \\
\hline TIERRA DEL COMUN QUE SE ALLA ROZADA PARA SIEMBRA & 18 & 0 \\
\hline DEHESA BOYAL & 895 & 1 \\
\hline DEHESAS DEL EXCELENTISIMO MARQUES DE MONTANA & 20031 & 13 \\
\hline TIERRA DEL COMUN DE VEZINOS CON PIEDRABUENA & 112955 & 71 \\
\hline EXIDO PARA ERAS & 3 & 0 \\
\hline TIERRA INUTIL DE NATURALEZA & 23095 & 15 \\
\hline TOTAL & 157998,7 & \\
\hline TIPOS DE TIERRA & SUPERFICIE (cuerdas) & DISTRIBUCIÓN PORCENTUAL (\%) \\
\hline TIERRAS DE REGADIO POR FUENTE & 19,8 & 0 \\
\hline TIERRAS DE SEMBRADURA Y SECANO & 543,9 & 0 \\
\hline TIERRA PROPIA PARA ROZAS & 438 & 0 \\
\hline $\begin{array}{l}\text { TIERRA DEL COMUN QUE SE ALLA ROZADA PARA } \\
\text { SIEMBRA }\end{array}$ & 18 & 0 \\
\hline DEHESA BOYAL & 895 & 1 \\
\hline DEHESAS DEL EXCELENTISIMO MARQUES DE MONTANA & 20031 & 13 \\
\hline TIERRA DEL COMUN DE VEZINOS CON PIEDRABUENA & 112955 & 71 \\
\hline EXIDO PARA ERAS & 3 & 0 \\
\hline TIERRA INUTIL DE NATURALEZA & 23095 & 15 \\
\hline TOTAL & 157998,7 & \\
\hline TIPOS DE TIERRA & SUPERFICIE (cuerdas) & DISTRIBUCIÓN PORCENTUAL (\%) \\
\hline TIERRAS DE REGADIO POR FUENTE & 19,8 & 0 \\
\hline TIERRAS DE SEMBRADURA Y SECANO & 543,9 & 0 \\
\hline TIERRA PROPIA PARA ROZAS & 438 & 0 \\
\hline $\begin{array}{l}\text { TIERRA DEL COMUN QUE SE ALLA ROZADA PARA } \\
\text { SIEMBRA }\end{array}$ & 18 & 0 \\
\hline DEHESA BOYAL & 895 & 1 \\
\hline DEHESAS DEL EXCELENTISIMO MARQUES DE MONTANA & 20031 & 13 \\
\hline TIERRA DEL COMUN DE VEZINOS CON PIEDRABUENA & 112955 & 71 \\
\hline EXIDO PARA ERAS & 3 & 0 \\
\hline TIERRA INUTIL DE NATURALEZA & 23095 & 15 \\
\hline TOTAL & 157998,7 & \\
\hline
\end{tabular}

Fuente: Elaboración propia. 
El número de vecinos que integraban la población era de quarenta vecinos y en el denominado Libro de lo Real se incluye una relación alfabética de los mismos.

No se indica el número de cabezas de ganado de cada categoría, sólo se testifica que tienen ganado bacuno de labrar sus eredades y zerril de cria, caballos para el servicio de su casa, pollinos, ganado de zerda y de cavrio; y a continuación el producto económico que obtienen de cada uno de esos tipos. Sí, en cambio, hay información pormenorizada sobre las colmenas, con un total de 435 e indicación de los propietarios.

Además, en el Catastro se apunta la existencia de dos molinos, así como quarenta vezinos y quarenta y una casas avitables y la mayor parte de ellas nezesitan repararse y ay otras diez arruinadas que por necesidad de sus dueños no se fabrican de nuevo. Respecto a los propios del Común se menciona la Dehesa Boyal donde pastaban los ganados de labor y cerril de los vecinos, que ocupaba 800 cuerdas; dado que no poseían otros propios con que hacer frente a los gastos que la villa tenía, cada año, con el consentimiento y acuerdo de los vecinos, el ganado merino de Jeronimo de la Cuesta, vecino de la villa de Desuella, entraba a pastar en ella mediante el pago de un arrendamiento. Además, sólo poseía como propios las casas consistoriales y el pósito real que no producía ninguna renta, por ello vendían las tierras baldíos de los sitios del Chorro, Valles e Igueruela al citado Jeronimo de la Cuesta para su ganado fino; también se vendía la tierra baldía de los sitios de la Bega, higuera y hozes que tenía por arrendamiento Don Diego de Haro, vezino de la ciudad de Ciudad Real, se indica que no pueden determinar el número de cuerdas comprendidas los citados baldíos por ser montuosas y de sierras como las demás que comprehende el termino.

A pesar de que en el mapa (Fig. 4), donde se representa el término, se dibuja una barca y un barquero cuando se responde a la pregunta $37^{\mathrm{a}}$ sobre si hay individuos que tengan embarcaciones, que naveguen en la mar o rios la respuesta es negativa.

En comparación con la situación del siglo XVI, la deforestación había avanzado de manera considerable, pues tan solo se menciona la existencia de árboles en la Dehesa Boyal y se hace referencia a los mismos como algunas encinas, el resto era monte bajo o matorrales. Desde el siglo XVIII, se permitía rozar todos los años para la siembra de tierras baldías señalándose previamente un sitio para hacerlo y después se repartía por suertes entre los vecinos labradores. En el momento de ejecución del Catastro se hallaban repartidas 18 fanegas en el sitio que llaman "Valle del Mimbre", donde hoy sobresale una notable turbera, y que era definido como "sitio valdio".

En ningún momento se alude a la existencia de zonas encharcadas ni se indica que las tierras baldías lo son porque están ocupadas por agua, sino que se trata de terrenos montuosos o pedregosos, en contraposición con zonas, regadas por ríos o arroyos, destinadas a cultivos de regadío. La comparación con las respuestas realizadas por la vecina localidad de Piedrabuena, que en el momento actual también posee bonales, es esclarecedora: existía una gran cantidad de agua que se destinaba para abasto del ganado del común y la sobrante se perdía porque ni 
siquiera se utilizaba para el riego. No es una información muy concreta, pero al menos alude a la existencia de agua sobrante.

Puede concluirse que, si bien no se habían experimentado demasiadas modificaciones en lo relativo a los usos del suelo, respecto al siglo XVI, el proceso de deforestación se había incrementado considerablemente a favor de una intensa roturación de las tierras para los cultivos.

\subsection{Los siglos XIX y XX, la primera mención a la existencia de prados naturales}

Para estas centurias unas de las primeras informaciones son las proporcionadas por los diccionarios de Miñano y de Madoz.

En 1826-28 (Diccionario de Miñano), esta localidad tenía 39 vecinos, 181 habitantes. Sólo se menciona un molino y se hace referencia a dos minas, la una sita en el aguadero que hay entre las dehesas de Checas y de las Barcas, cuyos metales eran plomo y plata y la segunda de plomo, en el valle de Santa María.

Por su parte, el Diccionario de Madoz (1846-1850) relata la existencia de los arroyos llamados Chico y Grande, inmediatos al pueblo que le surten de agua potable. Refiere la existencia de la Dehesa Boyal de 500 fanegas; la Higueruela de 400 , varios prados naturales en toda la ribera del río Guadiana y arroyos, y mucho monte de encina, roble, alcornoque, jaras y otros arbustos. Alude a 2 malos molinos harineros. El terreno es áspero, de secano y de buena calidad. La población referida por Madoz incluía 58 vecinos, 290 almas; en 1887, el censo la fija en 201 vecinos con 726 habitantes. El presupuesto municipal se cubre con los arriendos de pastos, ha de enfatizarse la información relativa a los prados naturales ubicados en la ribera del Guadiana y arroyos y que cabe suponer se localizaban en zonas donde hoy están los actuales bonales. Es digno de destacar cómo comienza a mencionarse de manera reiterada la presencia de prados naturales en las riberas de arroyos y en la del propio Guadiana; del mismo modo los molinos se califican como malos, quizás hay que suponer su escasa producción motivada por problemas de caudal.

La información sobre la incorporación de terrenos a los predios agrícolas sustrayéndolos a las zonas de bosque con el consiguiente proceso de erosión en las laderas, puede completarse, en paralelo a las informaciones contenidas en los diccionarios, con otra importante vía de consulta relacionada con el proceso de desamortización (eclesiástica y civil).

En lo relativo a la desamortización eclesiástica quedó al margen de la misma un ámbito muy concreto de la provincia de Ciudad Real, coincidente con una amplia zona del noroeste provincial cuyos rasgos, tanto naturales como humanos, la hacían escasamente atractiva a los compradores. Sin embargo, la causa de su marginación del proceso desamortizador fue esencialmente histórica debido entre otras razones a que entre los bienes comunales y de propios se incluían los pertenecientes a la Orden de Calatrava (es el caso de Puebla de Don Rodrigo o el de otros municipios, como Luciana o Agudo). Sin embargo, por estas mismas razones, todos ellos se 
verían notoriamente involucrados en la posterior desamortización general de Madoz (Del Valle Calzado, 1995),

La conocida como desamortización civil tuvo en la provincia de Ciudad Real una amplia repercusión, ya que se pusieron en venta bienes radicados en 92 términos municipales. En el conjunto provincial, el área más afectada fue la comarca Montes Norte, territorio con importantes aprovechamientos forestales relacionados con los Montes de Toledo y donde los bienes de propios tenían un indudable valor. Puebla de Don Rodrigo se incluyó en el grupo de municipios cuya venta de tierra no fue muy importante, situándose entre el 5 y el $10 \%$ del término (Del Valle Calzado, 1997). Otros pueblos limítrofes, como Piedrabuena, fueron desamortizados en más del $25 \%$ del término municipal ${ }^{12}$.

Ante el proceso desamortizador, los ayuntamientos se movilizaron mediante solicitudes tendentes a librar de la venta aquellas tierras que estimaban necesarias para el común de vecinos y se conservan expedientes informando de esta situación. En relación con Puebla de Don Rodrigo, se han localizado varios Expedientes de Incidencias (Archivo Histórico de Ciudad Real) en los que, en 1860, el Ayuntamiento pidió que se exceptuasen de la venta por aprovechamiento comunal además de la Dehesa Boyal los terrenos titulados Sierra de la Higuera, Tobarejo, Valle del Término ${ }^{13}$, Vega de Roble, Sierra de Chorro y de Castilnegro.

Junto a los Expedientes de Incidencias existían también los Expedientes de Investigación de aquellas propiedades que, supuestamente, los municipios ocultaban en un intento por librarlos de la venta. Así se ha encontrado, también en el Archivo Histórico de Ciudad Real ${ }^{14}$, varios de ellos fechados en agosto, octubre y noviembre de 1865 , en los cuales se intenta justificar la ocultación del terreno. Puede destacarse un escrito del 1 de octubre de 1865 ofreciendo información relativa al estado en que se encontraban los montes: Ciento doce mil nuebecientas setenta y tres cuerdas de tierra valdia y montuosa que produce algún pasto y es a veneficio del común de vecinos y sus ganados y además por acogida que hace la Villa (...) y dicha tierra en los sitios proporcionados también sirve para sembradura rozando el monte y cada un año se benefician y siembra treinta cuerdas (...) Y las veinte y tres mil y noventa y cinco cuerdas restantes, incultas por naturaleza, de sierras y pedregales y monte pardo.

Además, ante la reticencia de los ayuntamientos a poner en venta sus propios no sólo existía la presión que ejercía el Estado, sino también la que imponían algunos

\footnotetext{
${ }^{12}$ La superficie vendida en Puebla de Don Rodrigo fue 33.502 ha, 85 a y 72 ca., lo que representa el $8,1 \%$ del término. En Piedrabuena, como elemento de comparación, 26.416 ha, 66 a y 58 ca es decir el 46,4 \% del territorio municipal.

13 "El Valle" o "Valles del Término" constituye un amplio espacio que, en las fuentes documentales y cartográficas del siglo XX, coincide con el territorio de rañas que acoge a los bonales que jalonan la denomina Vereda de los Bonales e integrados en la Microrreserva Bonales de Puebla de Don Rodrigo.

${ }^{14}$ Expediente de Investigación de propiedades pertenecientes a propios y baldíos de Puebla de Don Rodrigo. 1865. Desamortización propiedades del Estado
} 
posibles compradores de estas tierras. Así en un escrito redactado en este sentido por un vecino de Piedrabuena se da información sobre el exiguo poblamiento vegetal que existía en el monte [CastilNegro] donde predomina ... brezo, lentisco, charnesca, jaras y algún chaparro y alcornoque.

En 1895, el Catálogo de Montes exceptuados de la Desamortización indica que en la localidad de Puebla de Don Rodrigo fueron liberados de venta los siguientes parajes:

- Sierra de Castilnegro (poblada con jara, como especie dominante y con quejigo y encina como especies subordinadas).

- Sierra del Chorro (especie dominante jara y subordinada, brezo).

- Sierra de la Higueruela (encina, como especie dominante y acebucho, enebro y alcornoque, como especies subordinadas).

- Tobarejo (también ocupada por la encina como especie dominante y acompañada de acebucho, enebro y alcornoque).

- Valles del Término (indicándose que la especie dominante es jara y las subordinadas acebucho, enebro y alcornoque).

- Vega del Roble (la especie dominante es la encina y las subordinadas aliaga y roble).

Debe resaltarse, a la luz de esta información que, a finales del siglo XIX, el proceso deforestador había progresado considerablemente: ya que en varios de los montes exceptuados la especie dominante era arbustiva: jara; en la Sierra del Chorro solo existía esta especie y brezo.

Una de las informaciones más reiterativas es la alusión a múltiples roturaciones en el término de Puebla de Don Rodrigo. Junto a la desamortización y a otros procedimientos que conllevan la privatización del patrimonio rústico municipal, se produjeron (como en otros municipios) roturaciones arbitrarias, durante la primera mitad del siglo XIX y posteriormente legitimadas, convirtiéndolas en propiedad privada.

Este proceso ha sido estudiado en Extremadura donde, y según los autores, las roturaciones arbitrarias fueron un importante procedimiento de transferencia de propiedades amortizadas a manos de particulares (Naranjo Sanguino et al., 2013). El fenómeno consistió en un proceso de usurpación de tierras concejiles por parte de vecinos que roturaban terrenos hasta entonces dedicados, en su mayoría, a pasto. Algunos ayuntamientos consintieron dicha práctica mientras otros persiguieron a quienes realizaban dichas roturaciones. A partir de los años 30 del siglo XIX, se promulgaron diferentes leyes ${ }^{15}$ que amparaban la actuación de los roturadores y les autorizaba a legitimar su propiedad (Naranjo Sanguino et al., 2013).

\footnotetext{
${ }^{15}$ En 1834 se promulgó una Real Orden (06/03/1834) que permitía a los roturadores solicitar la legitimación a cambio del pago de un canon perpetuo. La Ley de 6 de mayo de 1855 amparó a los que habían realizado roturaciones arbitrarias con anterioridad a mayo de 1837 y que seguían en posesión de las suertes roturadas.
} 
En el caso de Puebla de Don Rodrigo, existe constancia para el periodo 18921893, de numerosos casos de legitimación de propiedades, que ya estaban roturadas previamente, amparados en las nuevas y numerosas leyes aprobadas ${ }^{16}$. Así entre otros se han localizado diferentes expedientes (1892 y 1893) solicitando adjudicación de tierras que llevan ya varios años cultivando:

- Un expediente con fecha 1893, expone que encontrándose en condiciones de utilizar los beneficios que concede el R.D. de 29/08 1892 publicado en la Gaceta de 31 de mismo mes solicita la adjudicación de terrenos que viene cultivando Serapio Martin Ruiz en el paraje de Los Terreros. También en el mismo paraje Alejandro Martin Hernández.

- También se han localizado varios expedientes de legitimación de posesión de terrenos roturados en los pueblos de Abenojar-Villamayor (incluye las localidades de Abenojar, Arroba de los Montes, Alamillo, Fontanarejo, Membrilla, Mestanza, Puebla de Don Rodrigo, Saceruela, San Lorenzo, Villamayor). En uno de ellos ${ }^{17}$, año 1924, incoado a instancia de Juan Rodríguez Ramírez, se presenta una solicitud de legitimación de terrenos roturados en término municipal de Puebla de Don Rodrigo si bien fue declaraba nula la petición por estar probado el mejor derecho del Ayuntamiento. Este es un buen ejemplo del procedimiento seguido para estos casos:

1) Juan Rodríguez Ramírez vecino de esta villa, partido judicial de Piedrabuena en la provincia de Ciudad real expone que en este término municipal y sitio denominado Tomillares posee un terreno roturado por el mismo destinado a repoblación de chaparro y cereales de secano encontrándose antes de su roturación poblado de monte bajo, cuyo terreno adquirió en parte por compra privada y en parte por ser de su propiedad desde hace 4 años.

2) Los vecinos declaran que es cierto que tiene roturada esa finca desde hace más de 12 años. Uno de los vecinos dice que lo cultiva "toda vez que estaba de monte".

3) El ayuntamiento por su parte afirma: Es cierto que el referido señor Rodríguez (y otro vecino de esta villa llamado Braulio Zarate) en el año 1922 roturó un pequeño trozo de terreno en el sitio de referencia con intento de

\footnotetext{
${ }^{16}$ El 29 de agosto de 1893 se promulgó un Real Decreto por el que se legitimó las roturaciones de terrenos del Estado, incluyendo los desamortizables no excepcionados. Su artículo $7^{\circ}$ dispuso que los roturadores de terrenos del Estado o de Propios y Comunales de los pueblos que carecieran del título que autorizó la Ley de 6 de mayo de 1855 y el Real Decreto de 10 de julio de 1865 podrían legitimar la posesión, cualquiera que fuera la extensión, siempre que los tuvieran en cultivo con diez años de antelación y lo solicitaran en el plazo de un año. La legitimación había sido también reconocida por el artículo $42^{\circ}$ de la Ley de Presupuestos de 5 de agosto de 1893 y los Reales Decretos de 29 de agosto y 1 de septiembre del mismo año, artículo 40 de la Ley de Presupuestos de 30 de junio de 1895. Por Reales Decreto y Órdenes de 25 de junio y 28 de octubre de 1897 se regularon los procedimientos, y por Real Orden de 27 de agosto se aclararon, considerando no susceptibles de legitimación las realizadas en montes y terrenos comunales exceptuados de la desamortización.

${ }^{17}$ Expediente $n^{\circ} 47$, Negociado de propiedades. Administración de rentas públicas de la provincia de Ciudad Real.
} 
apropiárselo, pero denunciado el hecho por el guarda municipal de montes al Ayuntamiento, éste en sesión del día 9 de abril de 1922 acordó nombrar una comisión para llevar a efectos el deslinde y amojonamiento de terreno o finca del municipio y reivindicar la roturada".

Así mediante el procedimiento de la legitimación de las roturaciones arbitrarias se posibilitó el acceso a la propiedad de la tierra de un buen número de individuos, pequeños labradores y jornaleros, que no tuvieron capacidad para competir en las subastas de bienes nacionalizados.

Pero en definitiva el resultado para la evolución del medio natural fue el mismo: se pusieron en cultivos numerosas tierras que, hasta aquel momento, estaban ocupadas por monte y en numerosos casos, como en Los Terreros, sitos en las proximidades de las áreas ocupadas por los bonales. Estos factores: deforestación de las laderas, venta de bienes de propios y avance de la agricultura están íntimamente unidos.

Junto a la dedicación a los cultivos, la ganadería ha sido tradicionalmente una actividad importante en la localidad. Destaca el elevado número de cabezas superior a las 4.000 que se recogen en diferentes años (Fig. 4), cifra desdeñable si se compara con las de 2009: ganado bovino, 2.758; ovino, 26.807; caprino, 17.489 y porcino 310; lo que hace un total de 47.364 cabezas. Informaciones orales aluden a que en el momento actual (2015) habría unas 25.000 cabezas de ganado. A partir de los datos obtenidos en diversas fuentes documentales localizadas en el Archivo Histórico de Ciudad Real se ha podido reconstruir su evolución desde finales del XIX hasta principios del XX (Figura 5).

Una cabaña ganadera, con un elevado número de cabezas, necesita, lógicamente, pastos para alimentarse, así como zonas de abrevadero, de paso, etc. Siendo uno de los parajes más indicados al respecto los ocupados por terrenos con especies graminoides y amplio reservorio de agua como son los bonales. Pero no sólo es sustancial el número de cabezas de ganado sino también el tipo de ganadería. Es conocida la importancia en el proceso de deforestación del ganado cabrío como elemento depredador de las cubiertas vegetales o el del vacuno y los efectos del pisoteo en zonas especialmente frágiles como son los humedales de turba. Desde finales del siglo XIX, el ganado cabrío mostraba una mayor representación en el territorio; no obstante, en el siglo XXI (2009) domina en importancia la ganadería ovina si bien sigue manteniéndose un amplio número de cabezas de ganado en general (Fig. 5).

Para el siglo XX, se han examinado los fondos documentales depositados en el Archivo Municipal de Puebla de Don Rodrigo. Expedientes relativos a Trabajos de Repoblación Forestal, (años 1940-50); Autorización para la puesta en cultivo (195060); Autorización para la continuación de cultivos en distintos parajes del término municipal (1950-60); Planos de roturación de parcelas (1950-60); Expedientes y planos de vías pecuarias 1/50.000 (1966); Memorias del Ayuntamiento creadas con motivo de cotos de caza y litigios de caza (1950-60); Delimitación de montes (1945); Aprovechamientos de brezo para carboneo (1961); Autorizaciones de siembra por parte de los vecinos del pueblo de la Dehesa Boyal (1957); Propuestas 
para la mejora de pastizales con descuaje de matorral (1962); Proyectos de repoblación con castaños (1991); Plan de regeneración de pastizales (sin fecha); . Expedientes de consorcio entre el Patrimonio Forestal del Estado y el Ayuntamiento de Puebla de Don Rodrigo para repoblar determinados parajes del término.

Y entre los pertenecientes al Archivo Histórico Provincial de Ciudad Real: Copias de las actas generales del recuento de ganadería en el término municipal (finales del XIX - primeras décadas del siglo XX); Boletines Oficiales de la Provincia; Pliegos generales para los aprovechamientos forestales (finales del XIX y primeras décadas del siglo XX). Expedientes del Instituto de Colonización para la puesta en riego de la vega del Guadiana (1955-1963).

Figura 4. Número de cabezas de ganado desde 1891 a 1907 y en el año 2009. Para los años 1893,1894 y 1895 se carecen de datos.

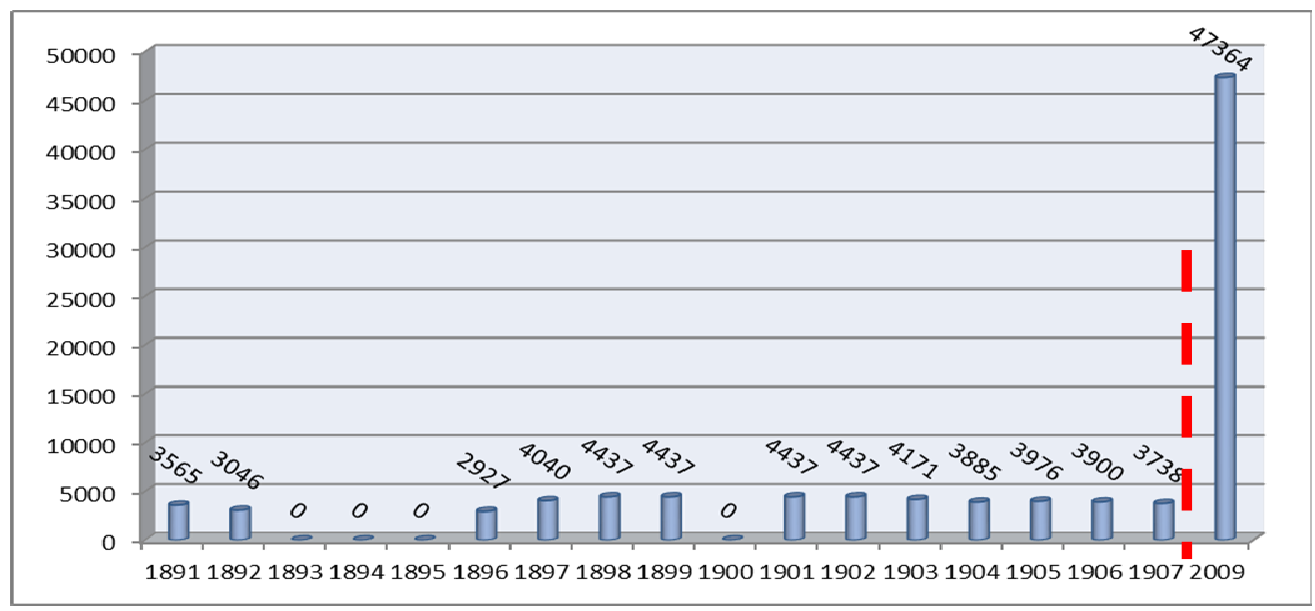

Fuente: Elaboración propia.

A través de su estudio se ha podido analizar, a mediados del siglo XX (1947), el intento de puesta en cultivo de parajes adyacentes a los bonales como son la Raña de La Laguna, y los parajes de Pizarrilla e inmediaciones del valle de Rechiceruelos. De igual modo, otros expedientes abordan la necesidad de llevar a cabo una notable repoblación forestal (1950 ha) en la zona norte del Monte "Valles del Término", debido a que unas 1900 ha se hallaban sin vegetación arbórea y sólo 50 contenían un "arbolado espontáneo".

Entre 1955 y 1957, nuevos expedientes municipales relatan cómo en 1955 se pusieron en cultivo numerosas parcelas ubicadas sobre las rañas de los Montes de Utilidad Púbica $n^{0} 15$ y 16, demandándose autorización para continuar los aprovechamientos agrícolas en 1957. En ellos, la petición se eleva a 645 ha y 536,5 ha en el Monte de Tobarejo" ( $\left.n^{\circ} 15\right)$ y a 361 ha y 366 en el Monte "Valles del Término" ( $\left.n^{\circ} 16\right)$. 
Entre los parajes donde se cita la posición de las parcelas figuran, en el "Monte de Tobarejo": la Vereda de Valdelobillos; el Barranco de la Casilla; ambos lados del $\mathrm{A}^{\mathrm{o}}$ de Valdelobillos y la Raña de La Laguna. Entre los lugares donde se emplazaban las parcelas del Monte "Valles del Término", se mencionan: Raños de los Torres y otros hasta el Barranco de Castillejos; Raña del Madroñal, Raña de Alconcillo y Raña del Aulagar (Fig. 17 y 18).

Figura 5. Número de cabezas de ganado dividido por tipos (1891-1907) ${ }^{18}$.

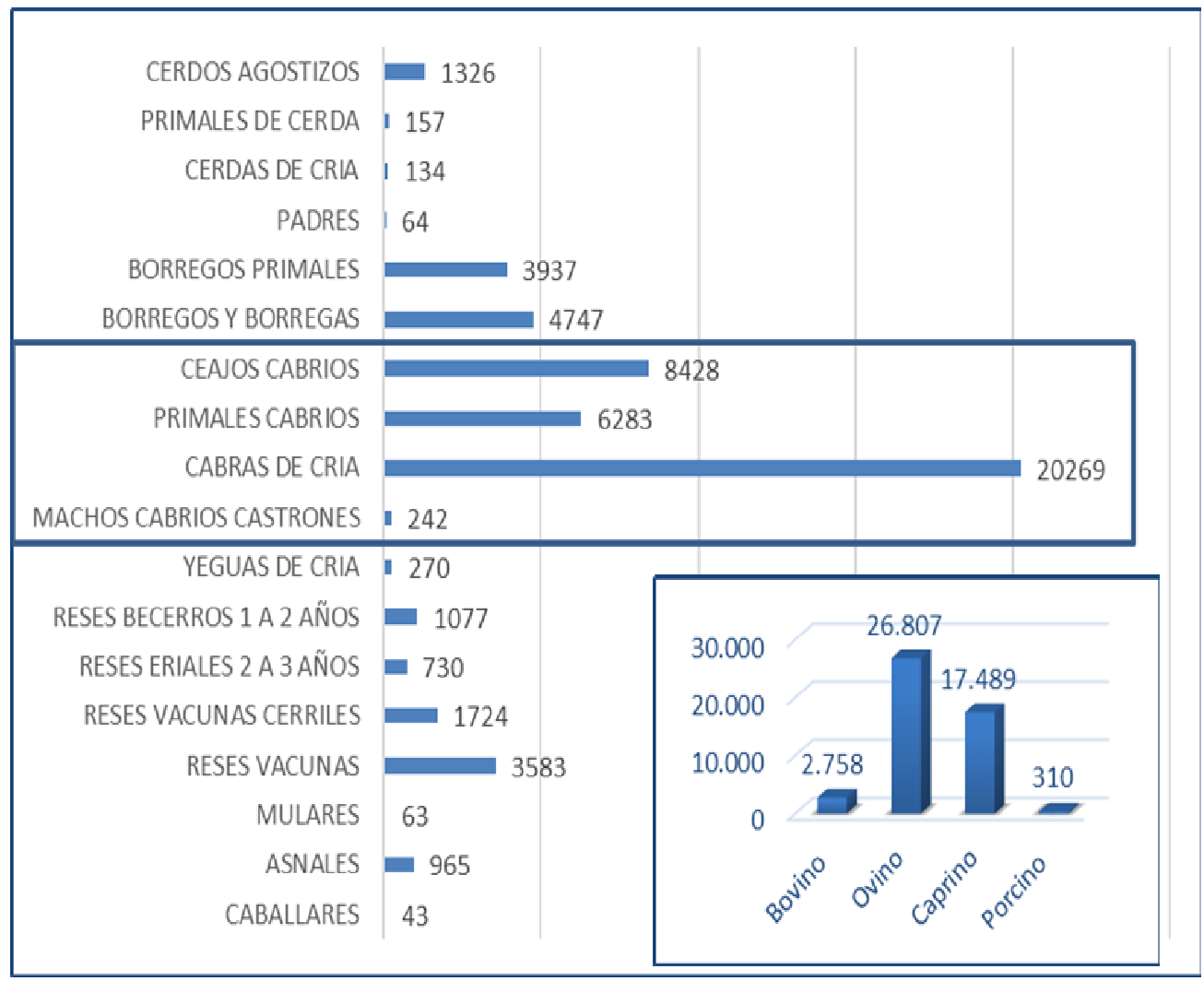

Fuente: Elaboración propia.

\footnotetext{
${ }^{18}$ A la derecha distribución de los tipos de ganado en 2009. Se puede apreciar cómo sigue siendo muy importante el ganado caprino aunque el primer lugar ahora es para el ganado ovino.
} 
La justificación para prolongar los cultivos se apoyaba en:

a) al ser las pendientes mínimas no se habían observado "erosiones" en el tiempo que se habían cultivado desde 1955;

b) los terrenos o "no estaban cubiertos por vegetación o estaban cubiertos de jara, brezo y labiérnago";

c) la finalidad de estas actuaciones sería mejorar las condiciones económicas "para resolver el problema social"19 y

d) los beneficios de la transformación superarían los perjuicios que se ocasionarían a la ganadería.

\section{Conclusiones}

La presencia en el momento actual de unos parajes de tan alto interés ecológico, en el interior de la Península Ibérica, como son los humedales higroturbosos de la provincia de Ciudad Real, está vinculada a una larga historia de actuación humana sobre su territorio. En el estudio de esta evolución, la información contenida en las fuentes documentales pone el acento en varios hechos relevantes:

1) La falta de mención a zonas encharcadas en el siglo XVI o XVIII, centurias con importantes fuentes textuales. Ni directa ni indirectamente se sugiere la presencia de parajes que no se pudieran cultivar por exceso de agua; tampoco se alude a la existencia de enfermedades como las fiebres tercianas vinculadas al encharcamiento y ámbitos donde hoy se localizan los bonales son referidos como ocupados por una vegetación residual, tras la deforestación, o bien de monte bajo sustitutorio del antiguo monte de quercíneas. Fue ya a mediados del siglo XIX, cuando la presencia de prados naturales donde pacía el ganado pasó a ser un hecho referido de modo reiterado

2) Por otra parte, y de igual manera a través de las fuentes documentales, se evidencia un intenso proceso deforestador que redujo el antiguo monte encinar a monte bajo o a matorrales siendo la jara la especie más mencionada. Llama también poderosamente la atención la relación de especies vegetales recogidas en las diferentes fuentes documentales consultadas (Tabla 2).

Las especies que se citan recrean un bosque mediterráneo característico donde la especie arbórea dominante era la encina acompañada por el alcornoque y sustituidas, cuando la deforestación se produce, por el jaral. En el siglo XIX, se alude a otros arbustos sin indicar especie. Es interesante denotar la escasa atención prestada a la existencia de especies atlánticas de brezos o de turbera que hoy son el elemento ecológico más representativo.

\footnotetext{
${ }^{19}$ El año 1957, la situación "social" aludida en los documentos parece que exigió, también, la necesidad de sembrar diferentes parcelas de la Dehesa Boyal a repartirse entre 754 vecinos
} 
Tabla 2. Relación de especies vegetales mencionadas en las diferentes fuentes consultadas.

\begin{tabular}{|c|c|c|}
\hline SIGLO XVI & SIGLO XVIII & SIGLO XIX \\
\hline jara & jara & jara \\
\hline encinas & $\begin{array}{c}\text { encinas algunas y chaparros } \\
\text { (matas altas de encina o de roble })\end{array}$ & $\begin{array}{c}\text { encina } \\
\text { (mucho monte de) }\end{array}$ \\
\hline alcornoque & & alcornoque \\
\hline quejigos & enebros & robles \\
\hline robles & matorrales & otros arbustos \\
\cline { 1 - 1 } & & \\
\hline lentisco & & \\
\cline { 1 - 1 } jaguarzo & &
\end{tabular}

Fuente: Elaboración propia.

3) Aunque la práctica de roturación para puesta en cultivo es muy anterior a la desamortización, a partir de ella se puso en marcha un fenómeno de intensa deforestación relacionada con una expansión de la agricultura. Este cambio en los usos de suelo conllevó: el aporte de abundantes coluviones a los fondos de los valles de los pequeños tributarios del rio Guadiana donde hoy se alojan las turberas; con ello se derivó una modificación en la dinámica de los flujos de agua contribuyendo a la conversión de cauces continuos en discontinuos y donde el agua se estanca y produce la acumulación de turba. En relación con este último aspecto mencionar cómo en el siglo XVI se alude al hecho de que los arroyos no dejan de correr al igual que el Guadiana.

Con este trabajo se muestra la enorme trascendencia que tiene el conocimiento de la evolución del paisaje a la hora de gestionarlo en el momento presente y como aquel se sustancia no solo en el reconocimiento de campo sino también en las fuentes documentales como un aliado indispensable.

\section{Bibliografía}

Alfonso XI, Rey de Castilla (1311-1350): Libro de la monteria que mando escrevir el muy alto y muy poderoso Rey Don Alonso de Castilla y de Leon, vltimo de este nombre. Acrecentado por Gonzalo Argote de Molina, Impreso en Sevilla por Andrea Pescioni, 1582

Archivo Histórico Provincial de Ciudad Real: Expedientes relativos al proceso desamortizador (Siglo XIX). Expedientes de incidencias. Caja H 1657.

Expediente de investigación de propiedades pertenecientes a propios y baldíos de Puebla de Don Rodrigo.1865. Caja H 1673.

Expediente de investigación de propiedades pertenecientes a propios y baldíos de Puebla de Don Rodrigo 1892. Caja 1286 n $^{\circ} 24$ cédula de $10^{a}$, clase $n^{\circ} 45,1^{\circ}$ octubre. 
Expedientes de legitimación de propiedades

Camarero Bullón, C. (2002): El Catastro de Ensenada, 1745-1756: diez años de intenso trabajo y 80.000 volúmenes manuscritos. CT, Catastro 46, 61-88.

Campos J. y Fernández de Sevilla F. (2009): Los pueblos de Ciudad Real en las Relaciones Topográficas de Felipe II Originales de cada uno de los pueblos, Biblioteca Real de El Escorial ms. J.I.14, f.344, Imprenta provincial de Ciudad Real, Diputación de Ciudad Real, 2. vols., 1168 pp.

Catastro del Marqués de la Ensenada (1753): Respuestas generales y Particulares del Catastro de Ensenada de Puebla de Don Rodrigo. Portal de Archivos Españoles. PARES. http://pares.mcu.es/Catastro/

Corchado Soriano, M. (1982). El Campo de Calatrava ( $3^{a}$ parte). Los pueblos y sus términos. Pueblo 40: Puebla de Don Rodrigo. Publicaciones Instituto de Estudios Manchegos, Dip. Provincial de Ciudad Real, 407-414.Del Valle Calzado, A. R. (1995): Desamortización eclesiástica en la provincia de Ciudad Real. Servicio de Publicaciones de la Universidad de Castilla La Mancha. Colección Tesis Doctorales, 401 pp.

Del Valle Calzado, A. R. (1997): La desamortización de Madoz en la provincia de Ciudad Real. Instituto de Estudios Manchegos (CSIC), Ciudad Real, 167 pp.

Fidalgo Hijano, C., González Martín, J. A., García Giménez, R. y Arteaga Cardineau, C. (2013) "Estudio Paleobotánico, Paleogeográfico dinámica y amenazas de la Microrreserva de los Bonales en el término municipal de Puebla de Don Rodrigo", contrato de investigación, Junta de Comunidades de Castilla La Mancha (inédito)

Florín Beltrán, M. (2012): Los bonales de Montes Norte: máquina del tiempo y puerta a otro mundo. En Gosálvez Rey, R.U. (Ed.) Montes Norte. Patrimonio natural y divulgación ambiental de un territorio singular. Asociación de Desarrollo Montes Norte, Ciudad Real, 111-131.

García Rayego, J.L. (1995): El medio natural en los Montes de Ciudad Real y el Campo de Calatrava., Ciudad Real. Biblioteca de Autores Manchegos, Diputación de Ciudad Real, $453 \mathrm{pp}$.

García Rayego, J.L. (1997a): El Medio Natural y sus unidades en el Sur de la Meseta Meridional. En: García Rayego, J.L. y González Cárdenas, E. (Eds.), Elementos del Medio Natural en la Provincia de Ciudad Real. Colección Estudios. Ediciones de la Universidad de Castilla La Mancha, Cuenca, 251 pp., 11-19.

García Rayego, J.L. (1997b): El Medio Físico de Los Montes. En: García Rayego, J.L. y González Cárdenas, E. (Eds.), Elementos del Medio Natural en la Provincia de Ciudad Real. Colección Estudios. Ediciones de la Universidad de Castilla La Mancha, Cuenca, 251 pp., 21-81.

García Río, R. (2000): Caracterización florística y ecológica de los bonales de Ciudad Real y planes para sus conservación como microrreservas Junta de Comunidades de Castilla La Mancha, inédito.

García Río, R. (2007): Flora y vegetación de interés conservacionista de Sierra Madrona y su entorno (Ciudad Real, Sierra Morena, España). Ecosistemas 16 (1) 97-111.

García Río, R. (2001): Una ojeada a los bonales de Montes Norte. Medio Ambiente CastillaLa Mancha, 6, 10-15. 
García Río, R. (2002): Flora protegida regional existente en las turberas de Ciudad Real. Conservación Vegetal. Boletín de la Comisión de Flora del Comité Español de la Unión Mundial para la Naturaleza 7, 7.

Hernández Pacheco, F. y Cabañas Ruesgas, F. (1952): Las características fisiográficas y geológicas del Guadiana entre Luciana y Puebla de Don Rodrigo. Boletín Real Sociedad Historia Natural, 50, 263-279.

Hervás y Buendía, I. (1914): Diccionario histórico, geográfico, biográfico y bibliográfico de la provincia de Ciudad Real (1899), Ciudad Real.

I.T.G.E. (1989): Mapa geológico de España 1/50.000 Hoja757. Puebla de Don Rodrigo, 81 pp.

Madoz, P. (1846 - 1850): Diccionario Geográfico-Estadístico-Histórico de España y sus posesiones de Ultramar, 16 vols., Madrid, (versión digitalizada Biblioteca Virtual Andalucía)

http://www.bibliotecavirtualdeandalucia.es/catalogo/consulta/registro.cmd? id=6353

Mingarro Martín, F. (1958): Las características fisiográficas y geomorfológicas del valle de Guadiana entre Luciana y Puebla de Don Rodrigo (Ciudad Real). Boletín Real Sociedad Historia Natural, 56, 168-184.

Miñano, S. (1826 -1828): Diccionario Geográfico y Estadístico de España y Portugal, 11 vols., (versión digitalizada Biblioteca digital de Castilla y León) http://bibliotecadigital.jcyl.es/i18n/consulta/registro.cmd?id=714

Naranjo Sanguino, M. A., Roso Díaz, M. y Ruiz Rodríguez. J. A. (2013): La propiedad de la tierra en la Extremadura del siglo XIX: Estado de la cuestión, Revista de Estudios Extremeños, 69 (1), 2013, 23-94.

Rivero González, S. (2003): Cosas de Antaño: Puebla de Don Rodrigo, Diputación Provincial, Ciudad Real, 280 pp. 